\title{
Evaluation of 2-SP transport medium for detection of Chlamydia trachomatis and Neisseria gonorrhoeae by two automated amplification systems and culture for chlamydia
}

\author{
O Dubuis, M Gorgievski-Hrisoho, D Germann, L Matter
}

\begin{abstract}
Aims-To assess the performance of 2-sucrose-phosphate based transport medium (2-SP) for the detection of Chlamydia trachomatis and Neisseria gonorrhoeae by an automated commercial polymerase chain reaction (PCR) and ligase chain reaction (LCR) compared to centrifugation culture on McCoy cells for $C$ trachomatis. Second, to compare both amplification systems for initial diagnostic testing of a low prevalence population for sexually transmitted diseases.

Methods-Four hundred and eighty one consecutive urogenital and conjunctival specimens were examined. All tests were performed on the same specimen collected with a dacron swab and transported in 2-SP medium. Samples that were positive by culture or by both PCR and LCR were considered to be true positives.

Results-The prevalences of $\boldsymbol{C}$ trachomatis and of $N$ gonorrhoeae were $2.7 \%$ and $0.4 \%$, respectively. PCR had a resolved sensitivity and specificity of $100 \%$ and $99.8 \%$, respectively, for $C$ trachomatis, and $100 \%$ and $98.9 \%$, respectively, for $N$ gonorrhoeae. LCR was $100 \%$ sensitive and specific for both pathogens. The resolved sensitivity of the shell vial assay was $85 \%$. No culture positive sample would have been missed by PCR or LCR. The inhibition rate for PCR was $4.8 \%$.

Conclusions-2-SP medium proved to be suitable for both PCR and LCR. It is not limited to any one test manufacturer and allows the performance of amplification techniques and viral and chlamydia culture from the same specimen. The LCR was more reliable than PCR on initial testing. However, hands on time is longer, and no amplification control is available for LCR.

(F Clin Pathol 1997;50:947-950)
\end{abstract}

Institute for Medical Microbiology,

University of Berne,

Friedbühlstrasse 51, 3010 Berne,

Switzerland

Correspondence to: Dr Dubuis.

Accepted for publication 15 July 1997
Keywords: 2-sucrose-phosphate medium; polymerase chain reaction; ligase chain reaction

Chlamydia trachomatis and Neisseria gonorrhoeae are the most frequent agents causing sexually transmitted diseases worldwide. ${ }^{12}$ In Sweden and Germany the incidence of gonococcal infections is only about 10 cases per 100000 and the situation is similar in Switzerland..$^{3-5}$ In the past decade, $C$ trachomatis has become the most common bacterium causing sexually transmitted disease in Europe, although data concerning the incidence are scarce. ${ }^{67}$

In recent years, the introduction of polymerase chain reaction (PCR) and ligase chain reaction (LCR) based methods has resulted in a substantial increase in sensitivity and (compared with most other non-culture methods) specificity for the detection of $C$ trachomatis and $N$ gonorrhoeae in urogenital swab specimens and urine..$^{8-16}$ The development of commercial, partially automated assays further simplified and shortened these procedures and made them available to a broader range of diagnostic laboratories. ${ }^{1017}$

One of our concerns as a diagnostic laboratory was the increasing number of manufacturer and test specific specimen collection and transport systems, each one with its particular handling directions and variable compatibility with other assays. The same specimen collection and transport kit should be suitable for amplification techniques and for viral and chlamydial culture. In this study, we evaluated the performance of 2-sucrosephosphate (2-SP) based transport medium for the detection of $C$ trachomatis and $N$ gonorrhoeae in urogenital and ocular swab specimens with automated LCR and PCR techniques compared with culture for chlamydia. $N$ gonorrhoeae culture was not an integral part of the study because it cannot be performed on samples transported in 2-SP, but culture results from a second swab were available for most patients. In addition, we wanted to determine which of the automated amplification systems would be more suitable for initial testing in our population with a low prevalence of sexually transmitted disease.

\section{Materials and methods}

POPULATION

Four hundred and ten consecutive cervical, 49 urethral ( 30 male, 19 female), and 22 conjunctival specimens sent to our laboratory for diagnostic purposes during a period of four months were tested prospectively by LCR and PCR for $C$ trachomatis and $N$ gonorrhoeae plus culture for chlamydia. Only the specimens collected with a dacron swab in 2-SP medium were included in the study ( $>90 \%$ of all submitted specimens). The Obstetrics and Gynaecology University Hospital of Berne provided $74.2 \%$ 
of the specimens, $10.6 \%$ were obtained from the Obstetrics and Gynaecology Clinic of the Bürgerspital at Solothurn, $3.5 \%$ from the Department of Internal Medicine, and 2.3\% from the Pediatric Clinics of the University Hospital of Berne, $2.1 \%$ were obtained from urologists, $3.3 \%$ from other laboratories, and $4 \%$ from other physicians or hospitals. Three hundred and sixty one swabs were available for $N$ gonorrhoeae culture.

SPECIMEN COLLECTION, TRANSPORT, AND PROCESSING

All specimens were collected with dacron swabs in 2-SP tubes. After arriving at our laboratory, the specimens were immediately split into two separate $1 \mathrm{ml}$ aliquots for amplification techniques and culture. For LCR and PCR $100 \mu \mathrm{l}$ was used and for culture $200 \mu \mathrm{l}$ was used. All tests were performed within three days. Before testing, the material was stored at $4^{\circ} \mathrm{C}$. The remaining material was frozen at $-80^{\circ} \mathrm{C}$.

\section{2-SP MEDIUM}

The 2-SP medium contained $0.2 \mathrm{M}$ sucrose, $0.0146 \mathrm{M} \mathrm{K}_{2} \mathrm{HPO}_{4} \cdot 3 \mathrm{H}_{2} \mathrm{O}, 0.054 \mathrm{M} \mathrm{KH_{2 }} \mathrm{PO}_{4}$ (all from Merck, Darmstadt, Germany), $2.5 \mathrm{mg} / 1$ amphotericin B (Squibb, Baar, Switzerland), 100-120 mg/l gentamicin (Seromed, Berlin, Germany), $10 \mathrm{~g} / 1$ bovine serum albumin (Sigma, Buchs, Switzerland), and $0.0025 \%$ phenol red solution (Flow Laboratories, Baar, Switzerland).

\section{AMPLIFICATION TECHNIQUES}

Sample preparation and amplification detection were performed in distinct laboratory areas. Standard precautions to avoid crosscontamination were adopted. ${ }^{18}$

\section{LIGASE CHAIN REACTION}

LCR was performed with the LCx system (Abbott Laboratories, Delkenheim, Germany). Sample preparation followed a modified urine processing protocol. After vortexing briefly, $100 \mu \mathrm{l}$ samples were transferred to a $1.5 \mathrm{ml}$ conical microcentrifuge tube (Sarstedt, Sevelen, Switzerland) and centrifuged for $15 \mathrm{~min}$ utes at $9000 \times g$ in a microcentrifuge. The supernatant was discarded and the pellet resuspended in $1 \mathrm{ml}$ urine resuspension buffer from the kit. The microcentrifuge tube was heated at $97^{\circ} \mathrm{C}$ for 15 minutes in a heatblock and left for another 15 minutes to cool to room temperature. Aliquots of $100 \mu \mathrm{l}$ were transferred to "ready for use" unit dose tubes from the kit containing $100 \mu \mathrm{l}$ of mastermix with four oligonucleotide probes specific for the $C$ trachomatis multicopy cryptic plasmid or the $N$ gonorrhoeae Opa-1 gene, respectively. Further processing was performed according to the manufacturer's instructions.

POLYMERASE CHAIN REACTION

PCR was performed with the COBAS Amplicor system (Roche Molecular Diagnostic Systems, Basel, Switzerland). All steps of the sample preparation, amplification, and detection were performed according to the manufac- turer's instructions. Briefly, $100 \mu \mathrm{l}$ of $2-\mathrm{SP}$ medium was added to $100 \mu \mathrm{l}$ of lysis buffer from the kit. After 10 minutes of incubation at room temperature, $200 \mu$ lof specimen diluent from the kit was added, followed by another 10 minutes of incubation at room temperature. An aliquot of $50 \mu \mathrm{l}$ of the processed sample was transferred to the previously prepared amplification tubes, containing a mastermix with biotinylated primers for the cryptic plasmid of $C$ trachomatis, the putative cytosine DNA methyltransferase gene of $N$ gonorrhoeae, and the amplification control (DNA plasmid with primer binding regions identical to $C$ trachomatis but unique probe binding region). A positive control for $C$ trachomatis (a negative control for $N$ gonorrhoeae) and for $N$ gonorrhoeae (a negative control for $C$ trachomatis) were run with each batch. The detection of the optional amplification control was applied to all samples. Amplification and detection are fully automated procedures with no intervening manipulations. Samples with a negative amplification control were retested after 10-fold dilution with the specimen diluent from the kit and 10 minutes heating in a heatblock at $95^{\circ} \mathrm{C} .{ }^{19}$

\section{CELL CULTURE}

Single pass cell culture was performed as a centrifugation culture (shell vial assay; SVA) on McCoy cell monolayers according to standard procedures. ${ }^{2021}$ Briefly, $200 \mu \mathrm{l}$ sonicated sample was inoculated on to $\mathrm{McCoy}$ cell shell vials and centrifuged for 45 minutes at $700 \times g$ at room temperature. The supernatant was discarded and Eagle's minimal essential medium supplemented with $10 \%$ inactivated fetal bovine serum and cycloheximide was added. The shell vials were incubated for 72 hours at $36^{\circ} \mathrm{C}$ in an atmosphere with $5 \% \mathrm{CO}_{2}$. After incubation they were fixed with $4^{\circ} \mathrm{C}$ cold acetone/ methanol and stained with chlamydia genus specific monoclonal antibodies (Argene, Varilhes, France) and fluorescein labelled monoclonal antimouse $\mathrm{F}\left(\mathrm{ab}^{\prime}\right)_{2}$ fragments (BioScience, Emmenbrücke, Switzerland). The number of inclusions was counted on a fluorescence microscope with a mercury 100 lamp at a magnification of $\times 200$. One or more typical inclusions were considered to be positive.

\section{RESOLUTION OF DISCREPANT SAMPLES}

Samples positive by either culture alone or with both amplification techniques were considered to be true positives. Samples positive or equivocal by just one amplification technique were considered discrepant. For $C$ trachomatis, all discrepant results could be resolved by repeating LCR and PCR from new aliquots, whereas for $N$ gonorrhoeae most discrepant results could be resolved this way. One repeatedly discrepant specimen for $\mathrm{N}$ gonorrhoeae was tested by a confirmatory PCR (16S rRNA; Roche, Basel, Switzerland). 
Table 1 Comparison of results by PCR, LCR, and SVA for Chlamydia trachomatis

\begin{tabular}{lccccc}
\hline Material & Total & LCP +ve & PCR $+v e$ & $S V A+v e$ & True +ve (\%) \\
\hline Cervical swabs & 410 & 11 & $12^{\star}$ & 10 & $11(2.7)$ \\
Urethral swabs & 49 & 2 & 2 & 1 & $2(4.1)$ \\
Conjunctival swabs & 22 & 0 & 0 & 0 & 0 \\
Total & 481 & 13 & 14 & 11 & $13(2.7)$
\end{tabular}

*one cervical swab was not reproducibly positive by PCR only and therefore was considered as false positive.

\section{STATISTICAL ANALYSIS}

Descriptive statistics were performed with the StatView II, version 4.01 software (Abacus Concepts, Berkeley, California, USA).

\section{Results}

Of the 410 cervical and 49 urethral specimens, $11(2.7 \%)$ and two (4.1\%), respectively, were positive for $C$ trachomatis by LCR and PCR. Ten $(91 \%)$ and one, respectively, of these positive specimens were also positive by SVA. Both positive urethral specimens were from men with urethritis. One cervical swab was initially equivocal by PCR with a negative amplification control but positive by both LCR and SVA. This sample turned out to be PCR positive on retesting after eliminating inhibitors with pretreatment (10-fold dilution and heating for 10 minutes at $\left.95^{\circ} \mathrm{C}\right)$. One culture and LCR negative sample was not reproducibly positive for $C$ trachomatis by PCR and, therefore, was considered to be a false positive (table 1 ).

One cervical and one male urethral specimen were positive for $N$ gonorrhoeae by both amplification techniques. The cervical specimen was initially negative by PCR with a negative amplification control and turned out to be positive on retesting, after elimination of inhibitors with the sample pretreatment described above. Four cervical samples were positive initially for $N$ gonorrhoeae by PCR only and negative on retesting. Three additional LCR negative samples were equivocal by PCR, one of them reproducibly. This sample was negative by the backup PCR of the manufacturer and, therefore, it was considered negative in our evaluation (table 2). As mentioned earlier, $N$ gonorrhoeae culture was not an integral part of this study. Nevertheless, $N$ gonorrhoeae culture on supplemented GC medium (Difco Laboratories, Detroit, Michigan, USA) in a $5 \% \mathrm{CO}_{2}$ atmosphere at $35^{\circ} \mathrm{C}$ could be performed with specimens collected at the same examination for 361 patients, and in particular, for all patients with positive or equivocal initial amplification results. Of the two confirmed positive samples the urethral swab was culture positive and the cervical specimen negative. None of the negative, equivocal, and initially discrepant samples was positive by culture.

Table 2 Comparison of results by PCR and LCR for Neissereria gonorrhoeae

\begin{tabular}{llllll}
\hline Material & Total & LCP +ve & PCR $+v e$ & Culture $+v e^{\star}$ & True $+v e$ \\
\hline Cervical swabs & 410 & 1 & $5 \dagger$ & $0 / 325$ & 1 \\
Urethral swabs & 49 & 1 & 1 & $1 / 24$ & 1 \\
Conjunctival swabs & 22 & 0 & 0 & $0 / 12$ & 0 \\
Total & 481 & 2 & 5 & $1 / 361$ & $2(0.4 \%)$ \\
\hline
\end{tabular}

${ }^{\star}$ positive culture results/total culture results available.

tfour cervical swabs were not reproducibly positive by PCR only and therefore were considered as false positives.
Despite the expectancy of dual infections no specimen was positive for both pathogens. ${ }^{2}$

Due to the lack of a built in amplification control, no data concerning inhibition with the LCR assay were available. The overall inhibition rate of the PCR assay assessed with the amplification control of the COBAS Amplicor was $4.8 \%$. The individual inhibition rates for cervical, urethral, and conjunctival swabs were $5.1 \%, 6.1 \%$, and $0.0 \%$, respectively.

PCR had a resolved sensitivity, specificity, and positive predictive value of $100 \%, 99.8 \%$, and $92.9 \%$ for $C$ trachomatis, and $100 \%$, $98.9 \%$, and $33.3 \%$ for $N$ gonorrhoeae, respectively. The LCR was $100 \%$ sensitive and specific for both pathogens. For $N$ gonorrhoeae, only the 361 patients with available culture results were taken into consideration. The resolved sensitivity of the SVA was $85 \%$.

\section{Discussion}

LCx and COBAS Amplicor are partially automated devices. For both assays the complete performance time varies between four and five hours, depending on the number of samples tested. As the COBAS Amplicor is a multiplex PCR and automation is more advanced, hands on time is shorter and the daily maximum possible sample through put for a skilled technician is higher than for the LCx (96 $v 48$ samples).

The performance of 2-SP with the Amplicor PCR has already been assessed, and the use of $2-\mathrm{SP}$ as a transport medium is approved by the manufacturer. ${ }^{122}$ For the LCx system very few data concerning this subject are available. ${ }^{22} \mathrm{We}$ demonstrated that 2-SP was also suitable for LCR. The only disadvantage of 2-SP is that it has to be stored at $4-8^{\circ} \mathrm{C}$. The shelf life of 2-SP kept at room temperature should, therefore, be evaluated for amplification techniques.

As a historical comparison, the prevalence of $2.7 \%$ for $C$ trachomatis and $0.4 \%$ for $N$ gonorrhoeae is similar to the prevalence we experienced before in a similar population (3.1\% for $C$ trachomatis, $0.6 \%$ for $N$ gonorrhoeae) with 755 samples collected in Roche Amplicor transport medium (334 tested with COBAS Amplicor, 421 tested with the manual Amplicor method).

The overall inhibition rate of $4.8 \%$ with COBAS Amplicor was clearly below the rate previously experienced by us $(\sim 18 \%)$ and described by others with the Amplicor transport medium. ${ }^{19}$ For the LCx system no amplification control is available. Therefore, we have no data assessing the inhibition rate with the LCx, but others have demonstrated an inhibition rate for cervical samples collected in LCx transport medium and spiked with elementary bodies of $4.4 \% .^{23}$

According to recently published evaluations of the amplification techniques-which are more sensitive than the former established gold standard of the culture-we used an extended gold standard. ${ }^{24}$ Samples positive by culture or by both amplification techniques were considered to be true positives. Both amplification techniques amplify a different sequence of the 
$C$ trachomatis cryptic plasmid and sequences from different genes for $N$ gonorrhoeae and, therefore, can be considered to be independent methods. ${ }^{62526}$

Sensitivity, specificity, and positive and negative predictive values of commercial LCR and PCR methods in male and female populations with various prevalences of sexually transmitted disease have been studied extensively for the diagnosis of $C$ trachomatis, and to a lesser extent for the diagnosis of $N$ gonorrhoeae, in different large scale studies. ${ }^{8} 1116$ 27-29 Due to the low prevalence of $2.7 \%$ for $C$ trachomatis infections in our study population (which is similar to that reported by Ninet et al in Geneva), ${ }^{23}$ and of less than $1 \%$ for $N$ gonorrhoeae, our data regarding sensitivity and positive predictive value should be interpreted with caution. Sensitivity of PCR depends upon the application of the optional amplification control to all samples. The reason for the isolated, not reproducibly positive PCR result for $C \mathrm{tra}-$ chomatis remains unclear, although contamination during the sample processing is the most likely explanation. The high rate of false positive and indeterminate results by the $N$ gonorrhoeae PCR which resulted in a positive predictive value of only $33.3 \%$ could be explained by the known cross-amplification of non-pathogenic neisseria species ( $N$ cinerea, $N$ subflava) which is described in the manufacturer's instructions. Unless the lack of specificity for $N$ gonorrhoeae is improved, the $N$ gonorrhoeae PCR with the COBAS Amplicor should not be considered to be a suitable tool for testing a population with a low prevalence of $N$ gonorrhoeae infections.

In conclusion, the most efficient combination in our laboratory setting was 2-SP with the LCx system. The ligase chain reaction was more reliable than PCR on initial testing, although the automation is not as fully developed as for the COBAS Amplicor, and no amplification control is available. 2-SP phosphate is a transport medium that allows amplification techniques, and viral and chlamydial culture to be carried out on the same specimen; this use of the same specimen collection and transport kit for both techniques will simplify sample collection for the clinician.

We thank Karin Baumann, Charlotte Bossi, Christine Brand, Therese Bürgi, Monika Stutz, Irene Stutz, and Anaïs Zaman fo the performance of the amplification techniques and SVAs. Th LCx reagents, the empty specimen collection tubes, and the dacron swabs were kindly provided by Abbott Diagnostic Division, Cham, Switzerland.

1 Handsfield HH, Sparling PF. Neisseria gonorrhoeae. In Mandell GL, Bennett JE, Dolin R, eds. Principles and practice of infectious diseases. New York: Churchill Livingstone, 1995:1909-26.

2 Jones RB. Chlamydia trachomatis. Trachoma, perinatal infections, lymphogranuloma venerum and other genital infections. In: Mandell GL, Bennett JE, Dolin R, eds. Principles and practice of infectious diseases. New York: Churchill ciples and practice of infectious

3 Kohl PK. Epidemiology of sexually transmitted diseases. Sex Transm Dis 1994;21 (suppl 2):81S-3S.

4 Bundesamt für Gesundheit. Gonorrhoe und SyphilisSchweiz. In: Übersicht über die Meldungen von InfektionskSchweiz. In: Ubersicht über die Meldungen von
rankheiten in der Schweiz 1995. 1996 Apr:13.

5 Paget WJ, Eichmann AR. Genital chlamydia infections in Switzerland [abstract]. Third European Chlamydia Meeting, Vienna, Austria. Sep 11-14, 1996:402.
6 Coutinho RA. Epidemiology of sexually transmitted diseases. Sex Transm Dis 1994;21 (suppl 2):1-2.

7 Piot P, Islam MQ. Sexually transmitted diseases in the 1990s. Sex Transm Dis 1994;21 (suppl 2):7-13.

8 Bass CA, Jungkind DL, Silverman NS, Bondi JM. Clinical evaluation of a new polymerase chain reaction assay for detection of Chlamydia trachomatis in endocervical specimens. F Clin Microbiol 1993;31:2648-53.

9 Bassiri M, Hu HY, Domeika MA, Burczak J, Svensson LO, Lee HH, et al. Detection of Chlamydia trachomatis in urine specimens from women by ligase chain reaction. $f$ Clin Microbiol 1995;33:898-900.

10 Chernesky MA, Lee HH, Schachter J, Burczak JD, Stamm WE, McCormack WM, et al. Diagnosis of Chlamydia trachomatis urethral infection in symptomatic and asymptomatic men by testing first-void urine in a ligase chain reaction assay. $\mathcal{F}$ Infect Dis 1994;170:1308-11.

11 Ching S, Lee HH, Hook III EW, Jacobs MR, Zenilman J. Ligase chain reaction for detection of Neisseria gonorrhoeae in urogenital swabs. $\mathcal{f}$ Clin Microbiol 1995;33:311114

12 Dille BJ, Butzen CC, Birkenmeyer LG. Amplification of Chlamydia trachomatis DNA by ligase chain reaction. $\mathcal{f}$ Clin Microbiol 1993;31:729-31.

13 Doornum GJJ, Buimer $M$, Prins $M$, Henquet CJM, Coutinho RA, Plier PK, et al. Detection of Chlamydia trachomatis infections in urine samples from men and women by ligase chain reaction. $\mathcal{f}$ Clin Microbiol 1995;33:2042-7.

14 Lee HH, Chernesky MA, Schachter J, Burczak JD, Andrews WW, Muldoon S, et al. Diagnosis of Chlamydia trachomatis genitourinary infections in women by ligase chain reaction assay of urine. Lancet 1995;345:213-16.

15 Mahony JB, Luinstra KE, Sellors JW, Chernesky MA. Comparison of plasmid- and chromosome-based polymerase chain reaction assays for detecting Chlamydia trachomatis nucleic acids. ₹ Clin Microbiol 1993;31:1753-8.

16 Schachter J, Stamm WE, Quinn TC, Andrews WW, Burczak JD, Lee HH. Ligase chain reaction to detect Chlamydia trachomatis infection of the cervix. $f$ Clin Microbiol 1994;32:2540-3.

17 Direnzo S, Jungkind D, Silverman N, Park H. Comparison of manual AMPLICOR PCR to the automated COBAS AMPLICOR system for simultaneous detection of Chlamydia trachomatis and Neisseria gonorrhoeae [abstract]. In: Program and abstracts of the 95th General Meeting of the American Society for Microbiology. 1995 May 21-25; of the American Society for Microbiology. 1995 May 21-25;
Washington, DC: American Society for Microbiology, 1995:86.

18 Kwok S, Higuchi R. Avoiding false positives with PCR. Nature 1989;339:237-8.

19 Verkooyen RP, Luijendijk A, Goessens WHF, Huisman WM, Kluytmans JAJW, vanRijsoort-vos JH, et al. Detection of PCR-inhibitors in cervical specimens using the AMPLICOR Chlamydia trachomatis assay [abstract]. In: Program and abstracts of the 95th General Meeting of the American Society for Microbiology. 1995 May 21-25; Washington, DC: Society for Microbiology. 1995 May 21-25; Washin
American Society for Microbiology, 1995:84

20 Ripa KT, Mårdh PA. Cultivation of Chlamydia trachomatis in cycloheximide-treated McCoy cells. $\mathcal{F}$ Clin Microbio 1977;6:328-31

21 Thomas BJ, Evans RT, Hutchinson GR, Taylor-Robinson D. Early detection of chlamydial inclusions combining the use of cycloheximide-treated McCoy cells and immunofluorescence staining. $\mathcal{F}$ Clin Microbiol 1977;6:285-92.

22 Van der Pol B, Williams JA, Pool RW, Wools K, Jones RB Amplification by PCR and LCR of specimens collected in culture transport medium for the detection of Chlamydia culture transport medium for the detection of Chlamydia ing, Vienna, Austria, Sep 11-14, 1996:282.

23 Ninet B, Rohner P, Delaspre O, Auckenthaler R. Detection of Chlamydia trachomatis by ligase chain reaction in a low incidence population [abstract]. 55th Annual Meeting of the Swiss Society of Microbiology, Berne, Switzerland, Feb 29-Mar 1, 1996:140.

24 Chernesky MA, Jang D, Lee HH, Burczak JD, Hu H, Sellors $\mathrm{J}$, et al. Diagnosis of Chlamydia trachomatis infections
in men and women by testing first-void urine by ligase chain reaction. F Clin Microbiol 1994;32:2682-5.

25 Hatt C, Ward ME, Clarke IN. Analysis of the entire nucleotide sequence of the cryptic plasmid of Chlamydia trachomatis serovar L1. Evidence for involvement in DNA replication. Nucleic Acids Res 1988;16:4053-67.

26 Loeffelholz MJ, Lewinski CA, Silver SR, Purohit AP, Herman SA, D Buonagurio A, et al. Detection of Chlamydia trachomatis in endocervical specimens by polymerase chain reaction. $\mathcal{F}$ Clin Microbiol 1992;30:2847-51.

27 Catry MA, Borrego MJ, Cardoso J, Azevedo J, Santo I. Comparison of the Amplicor Chlamydia trachomatis test and cell culture for the detection of urogenital chlamydial infections. Genitourin Med 1995;71:247-50.

28 Skulnick M, Chua R, Simor AE, Low DE, Khosid HE, Fraser $\mathrm{S}$, et al. Use of the polymerase chain reaction for the detection of Chlamydia trachomatis from endocervical and urine specimens an asymptomatic low-prevalence population of women. Diagn Microbiol Infect Dis 1994;20:195201.

29 Wiesenfeld HC, Uhrin M, Dixon BW, Sweet RL. Diagnosis of male Chlamydia trachomatis urethritis by polymerase chain reaction. Sex Transm Dis 1995;21:268-71. 